\title{
Attachment and release of spermatozoa from the caudal isthmus of the hamster oviduct
}

\author{
T. T. Smith* and R. Yanagimachi \\ Department of Anatomy and Reproductive Biology, University of Hawaii Medical School, \\ Honolulu, Hawaii, 96822 USA
}

\begin{abstract}
Summary. Female hamsters were mated shortly after the onset of oestrus. At 3 or $6 \mathrm{~h}$ after mating, the right oviduct was flushed in situ with 30,90 or $180 \mu l$ medium to remove spermatozoa from the lumen, leaving only those firmly attached to the isthmic mucosa of the oviduct. When eggs were recovered from oviducts at $20 \mathrm{~h}$ after flushing the majority were fertilized, indicating that the spermatozoa that were firmly attached to the mucosa were capable of detaching and ascending to the ampulla to fertilize eggs. Neither the time of flushing nor the volume of flushing medium had a significant effect on the percentage of spermatozoa that remained in the isthmus after flushing. These results suggest that there is no change in the surface of the oviduct mucosa that causes the release of spermatozoa from the caudal isthmus near the time of ovulation. When uncapacitated spermatozoa were introduced into the oviduct, many of them attached to oviducal mucosa, while capacitated spermatozoa did not. This indicates that it is a change in the sperm surface, rather than the mucosal surface, that causes the release of spermatozoa, i.e. spermatozoa remain attached to the isthmic mucosa until they become capacitated and then detach and migrate to the ampulla to fertilize the eggs.
\end{abstract}

Keywords: sperm transport; sperm storage; epithelium; fertilization; hamster; oviduct

\section{Introduction}

When the female hamster mates shortly after the onset of oestrus, thousands of spermatozoa quickly enter the isthmic region of the oviduct (Yanagimachi \& Chang, 1963; Smith et al., 1987). These spermatozoa remain in the isthmus for nearly $8 \mathrm{~h}$ until about the time of ovulation when a relatively small number ascend to the ampulla to participate in fertilization (Smith et al., 1987). Sperm storage in the isthmus also occurs when females mate during ovulation, but the storage period is shorter (Smith et al., 1987). Sperm storage in the oviducal isthmus during the preovulatory period is not unique to the hamster. It also occurs in guinea-pigs (Yanagimachi \& Mahi, 1976), rabbits (Overstreet \& Cooper, 1978), sheep (Hunter et al., 1982), pigs (Hunter, 1984), cows (Hunter \& Wilmut, 1984), and mice (Suarez, 1987). Little is known about how the spermatozoa are sequestered in the isthmus. Several mechanisms have been suggested, including localized constriction of the isthmus (Suarez, 1987), the trapping of spermatozoa in viscous isthmic mucus (Jansen, 1978), depressed sperm motility in the isthmus (Overstreet \& Cooper, 1975; Suarez, 1987), and sperm attachment to the mucosal surface (Cooper et al., 1979; Flechon \& Hunter, 1981; Smith et al., 1987; Suarez, 1987).

When we removed hamster spermatozoa selectively from the lumen and mucosal surface of the oviducal isthmus by flushing, we found that the percentage of live spermatozoa was much higher among spermatozoa attached to the mucosal surface than those free in the lumen (Smith \&

*Present address: Worcester Foundation for Experimental Biology, 222 Maple Avenue, Shrewsbury, MA 01545, USA 
Yanagimachi, 1990), implicating the importance of the mucosal surface in maintaining sperm viability during storage. However, we did not determine whether the spermatozoa attached to the isthmic mucosa are capable of detaching and ascending to the ampulla to fertilize eggs. The present study was initiated to answer this question and to determine whether the degree of sperm attachment is altered by temporal changes in the mucosal surface and/or the capacitation status of the spermatozoa.

\section{Materials and Methods}

Animals and mating. The female golden hamsters used in this study were raised to weaning under regular lighting conditions (lights 05:00 to 19:00 h). At weaning, females were transferred to a cabinet with a reversed light cycle (lights 17:00 to $07: 00 \mathrm{~h})$ and housed in groups of up to 6 in large cages $(15 \times 27 \times 43 \mathrm{~cm})$ until maturity. Under reversed light conditions, mature females ( $2-4$ months old) exhibited behavioral oestrus by $06: 30 \mathrm{~h}$ and ovulated between $12: 30$ and 14:00 h of every 4th day. Mature females were checked every day at $08: 00 \mathrm{~h}$ for the presence of transparent mucus in the vagina indicating that the female was in oestrus (Orsini, 1961). An oestrous female was then placed in a large cage containing a pair of mature (4-8 months old) sibling males of proven fertility. Mating began within $5 \mathrm{~min}$. The males used in this study were maintained under regular lighting conditions (lights 05:00 to 19:00 h).

Flushing of the oviduct in situ. We previously developed a technique to remove spermatozoa selectively from surgically isolated oviducts (Smith \& Yanagimachi, 1990). For the present study, we modified this technique to allow selective removal of spermatozoa from the oviduct in situ. At 3 or $6 \mathrm{~h}$ after the onset of mating, females were removed from the male's cage, anaesthetized with ether and the right oviduct was exposed through a $1-\mathrm{cm}$ flank incision. The first loop of the ampulla was ligated and pierced with a micropipette attached to a $100-\mu l$ glass syringe mounted in a microinjector (Fig. 1). When an oviduct was flushed before ovulation (at 11:00 h, i.e. $3 \mathrm{~h}$ after mating), the tip of the micropipette was inserted through the wall of the ampulla. When an oviduct was flushed during ovulation (at 14:00 h, i.e. $6 \mathrm{~h}$ after mating), the tip was inserted through the wall of the cephalic isthmus to leave the egg cumulus complex undisturbed.

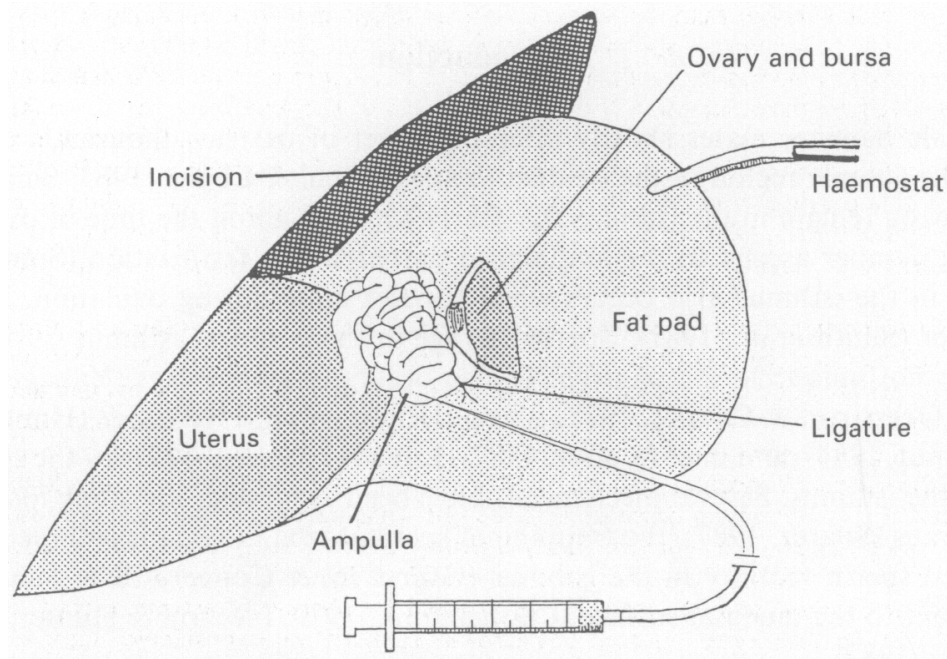

Fig. 1. Procedure for flushing the hamster oviduct in situ. The right oviduct is exposed through a flank incision and held in place by a $10-\mathrm{cm}$ haemostat. The $1 \mathrm{st}$ loop of the ampulla is ligated with a suture. A medium-filled micropipette (drawn to an $80-\mu \mathrm{m}$ tip and ground to a bevelled $20^{\circ}$ point) is inserted into the ampulla or cephalic isthmus (see text). The pipette is connected to $30 \mathrm{~cm}$ of Silastic tubing that is in turn connected to a 100- $\mu$ l Hamilton syringe mounted in a microinjector. During flushing, the medium and apparatus are kept warm $\left(\sim 37^{\circ} \mathrm{C}\right)$ under an infrared lamp. 
The medium used for flushing was Ham's F-12 (Sigma Chemical Co., St Louis, MO, USA) supplemented with $1.2 \mathrm{~mm}$-calcium lactate (Mann Research Laboratories, New York, NY, USA), $0.5 \mathrm{~mm}$-hypotaurine (Sigma), $59 \mu \mathrm{g}$ gentamicin sulphate/ml (Sigma) and $12 \mathrm{mg}$ bovine serum albumin/ml (Fr V, Calbiochem, San Diego, CA, USA). The $\mathrm{pH}$ of the medium was 7.3 when equilibrated with $5 \% \mathrm{CO}_{2}$ in air. The volume of medium used for flushing was 30,90 or $180 \mu \mathrm{l}$. For the $180 \mu \mathrm{l}$ volume the oviduct was flushed twice with $90 \mu \mathrm{l}$, waiting 3 min between flushes. Our preliminary experiments showed that a slower rate of flushing $(25 \mu \mathrm{l} / \mathrm{min})$ did not remove as many spermatozoa as a faster rate $(6 \mu \mathrm{l} / \mathrm{sec})$, and so the faster rate of flushing was used in this study. Immediately after flushing, the ligature was removed from the ampulla.

To prevent spermatozoa in the uterus (including those carried down to the uterus by fiushing) from entering the flushed oviduct, $0.2 \mathrm{ml}$ saline $(0.9 \%(\mathrm{w} / \mathrm{v}) \mathrm{NaCl})$ was introduced into the right uterine lumen through a 20-gauge needle attached to a $1-\mathrm{ml}$ tuberculin syringe. The diluted uterine spermatozoa were drawn into the syringe and discarded. The uterine lumen was then filled with distilled water $(0.2 \mathrm{ml})$ and left for $1-2 \mathrm{~min}$ to kill any remaining spermatozoa. The distilled water was withdrawn and the uterine lumen was rinsed with saline. The uterine apex (intramural isthmus) was then ligated with a 6-0 suture (Dermalon: Davis and Geck, Manati, Puerto Rico) to prevent any spermatozoa that remained in the uterotubal junction from entering the isthmus. The oviduct was returned to the peritoneal cavity and the incision closed. The left side of the genital tract of each female was left untouched and served as the control. The entire operation took about $10 \mathrm{~min}$. As an additional control, sham operations were performed on 3 females. Sham operations were performed in a manner identical to the flushing procedure outlined above (including puncture of the oviduct) except that oviducts were not flushed.

To determine the effect of flushing the oviduct in situ on the viability of the spermatozoa remaining in the oviduct, oviducts were removed after flushing in situ and spermatozoa were observed directly through the oviducal wall (Smith \& Yanagimachi, 1990).

Examination of eggs after flushing in situ. At about $20 \mathrm{~h}$ after flushing the oviducts, females were killed with $100 \%$ $\mathrm{CO}_{2}$ and their oviducts were removed. The right (experimental) and left (control) oviducts were placed in separate watchglasses and flushed with $0.2 \mathrm{ml} \mathrm{F-12}$ medium. Recovered eggs were mounted between a slide and coverslip and examined for evidence of fertilization (the presence of a sperm tail in the ooplasm) and development.

Determination of the number of spermatozoa remaining in the oviduct after fushing. To interpret the results of the above fertilization experiments, it was necessary to determine the number of spermatozoa that remained attached to the isthmic mucosa after flushing in situ. To accomplish this, right oviducts were flushed with 30,90 or $180 \mu \mathrm{l}$ of medium at $3 \mathrm{~h}$ after the onset of mating as previously described. Immediately after flushing, the right and left oviducts were fixed with AFA fixative (Orsini, 1962), serially sectioned $(10 \mu \mathrm{m})$ and stained. The number of spermatozoa in the caudal isthmus was determined using the method of Smith et al. (1987). Three females were used for each experiment. Due to the large degree of variability in the number of spermatozoa found in the caudal isthmus of different oviducts (see Table 2), the percentage, rather than the absolute number, of spermatozoa remaining in the caudal isthmus was used for comparison. The percentage of spermatozoa remaining in the caudal isthmus after flushing was calculated from: [no. of spermatozoa in the flushed caudal isthmus/no. of spermatozoa in the unflushed caudal isthmus] $\times 100$. This calculation is based on the assumption that equal numbers of spermatozoa enter the right (flushed) and left (control) oviducts. Although there is a variation in the number of spermatozoa found in the right and left oviducts of an individual female and between individuals, neither side consistently contains a large number of spermatozoa (Smith et al., 1987). In a previous study (Smith \& Yanagimachi, 1990), we showed that the number of spermatozoa attached to the mucosa of the caudal isthmus remains constant during the pre- and peri-ovulatory periods. Therefore, the percentage of spermatozoa remaining in the caudal isthmus provides a valid means of comparison.

Introduction of uncapacitated and capacitated spermatozoa into the oviducts of unmated females. To determine whether sperm attachment to the oviducal mucosa is influenced by the capacitation status of the spermatozoa, suspensions of uncapacitated and capacitated spermatozoa were introduced into the oviduct and the spermatozoa were assessed for their ability to attach to the mucosa. Uncapacitated and capacitated spermatozoa were prepared as follows. A highly motile suspension of cauda epididymal spermatozoa were prepared by a 'swim-up' method (Uto $e t$ al., 1988) in a modified Tyrode's medium, m-TALP (Yanagimachi, 1982), containing 0.5 mm-hypotaurine instead of taurine. An aliquant $(0.3 \mathrm{ml})$ of sperm suspension $\left(1-2 \times 10^{6} \mathrm{cells} / \mathrm{ml}\right)$ was incubated under mineral oil (Squibb, Princeton, NJ, USA) for 0 to $3 \mathrm{~h}$ (Yanagimachi, 1982). Spermatozoa incubated for $3 \mathrm{~h}$ were considered 'capacitated'. At this time, more than $90 \%$ of these spermatozoa exhibited hyperactivated motility, but the incidence of spontaneous acrosome reaction was less than $1 \%$ as assessed by phase-contrast microscopy. Spermatozoa used immediately after 'swim-up' ( $0 \%$ hyperactivated, $0 \%$ acrosome reacted) were considered 'uncapacitated'.

Oviducts were isolated from mature unmated females at 11:00 h (about $2-3 \mathrm{~h}$ before ovulation), placed in a prewarmed $\left(37^{\circ} \mathrm{C}\right)$ watchglass and $50 \mu \mathrm{l}$ of either capacitated or uncapacitated sperm suspension were introduced into each oviduct. Approximately $5 \mu l$ (about $7.5 \times 10^{3}$ spermatozoa) of sperm suspension were retained by each oviduct. After introducing sperm suspensions, 6 oviducts were immediately transferred into prewarmed medium and, $15 \mathrm{~min}$ later, each oviduct was flushed with $50 \mu \mathrm{l}$ warm m-TALP to remove any unattached or loosely attached spermatozoa. These oviducts were fixed, serially sectioned, and the number of spermatozoa attached to the oviducal mucosa was counted. Four other oviducts were each mounted between a slide and coverslip, slightly compressed and examined for the behaviour of spermatozoa within the oviduct by viewing them through the oviducal wall (Smith \& Yanagimachi, 1990 ) before and after flushing with $50 \mu \mathrm{l}$ warm m-TALP medium. 


\section{Results}

\section{Effect of in-situ flushing on the viability of oviducal spermatozoa}

When observed through the oviducal wall, the spermatozoa that remained in the oviduct after flushing in situ exhibited vigorous flagellar movement. However, they were not swimming freely in the lumen. Instead, all spermatozoa were seen attached to the mucosa by the rostral surface of their heads. No immotile (dead) spermatozoa were seen in the oviduct after flushing. This method appeared to have no adverse effect on the spermatozoa remaining in the oviduct.

\section{Fertilization after flushing of the oviduct in situ}

Regardless of the volume of medium used for flushing $(30,90$ or $180 \mu l)$, high percentages of the eggs recovered from flushed oviducts were fertilized (Table 1), indicating that the spermatozoa which remained attached to the isthmic mucosa during flushing were capable of later detaching and ascending to the ampulla to fertilize eggs. Similarly, high percentages of eggs recovered from sham-operated oviducts were fertilized. However, the percentages of 2-celled eggs recovered from flushed and sham-operated oviducts were lower than in control (unflushed) oviducts (Table 1).

Table 1. Fertilization after flushing the hamster oviduct in situ with various volumes of medium*

\begin{tabular}{lccccc}
\hline \multirow{2}{*}{$\begin{array}{l}\text { Volume of } \\
\text { flushing } \\
\text { medium }(\mu \mathrm{l})\end{array}$} & $\begin{array}{c}\text { No. of } \\
\text { oviducts }\end{array}$ & $\begin{array}{c}\text { No. of eggs } \\
\text { examined }\end{array}$ & $\begin{array}{c}\text { \% Eggs } \\
\text { fertilized }\end{array}$ & $\begin{array}{c}\text { Pronuclear } \\
\text { stage }\end{array}$ & $\begin{array}{c}\text { 2-cell } \\
\text { stage }\end{array}$ \\
\hline 30 & 5 & 33 & 91 & 53 & 47 \\
0 (control) & 5 & 25 & 100 & 26 & 74 \\
90 & 5 & 18 & 100 & 50 & 50 \\
0 (control) & 5 & 31 & 100 & 7 & 93 \\
180 & 5 & 28 & 87 & 64 & 36 \\
0 (control) & 5 & 25 & 100 & 16 & 84 \\
0 (sham surgery) & 3 & 19 & 93 & 53 & 37 \\
0 (control) & 3 & 20 & 100 & 10 & 90 \\
\hline
\end{tabular}

${ }^{*}$ At $20 \mathrm{~h}$ after flushing, i.e. $18 \mathrm{~h}$ after ovulation.

\section{Number of spermatozoa remaining in the isthmus after flushing in situ}

Neither the volume of flushing medium $(30,90,180 \mu \mathrm{l})$ nor the time of flushing ( 3 or $6 \mathrm{~h}$ after mating) had a significant effect on the percentage of spermatozoa remaining in the caudal isthmus (Table 2).

\section{Binding of uncapacitated and capacitated spermatozoa to the oviducal mucosa}

There was a significant difference ( $t$ test) between uncapacitated and capacitated spermatozoa with respect to their ability to attach to both the isthmic mucosa $(P \leqslant 0.5)$ and the ampullary mucosa $(P \leqslant 0.5)$. Capacitated spermatozoa were virtually unable to attach, whereas many uncapacitated spermatozoa attached firmly to both the isthmic and ampullary mucosa (Table 3). When we examined spermatozoa through the oviducal wall immediately after introducing the sperm suspensions, capacitated (hyperactivated) spermatozoa swam freely within the lumen and 
Table 2. Mean number ( \pm s.d.) of spermatozoa in the caudal isthmus before and after flushing the hamster oviduct in situ at different times after mating or with different volumes of medium

\begin{tabular}{lcccc}
\hline \multirow{2}{*}{$\begin{array}{l}\text { Time of } \\
\text { flushing }\end{array}$} & $\begin{array}{c}\text { Volume }(\mu \mathrm{l}) \\
\text { of medium }\end{array}$ & Before flushing & After flushing & $\begin{array}{c}\text { \% Spermatozoa } \\
\text { remaining } \\
\text { in isthmus }\end{array}$ \\
\cline { 2 - 4 } & 30 & $19194 \pm 4494$ & $8008 \pm 925$ & $43 \pm 6 \cdot 3$ \\
3h hafter & 90 & $15614 \pm 6240$ & $5599 \pm 2332$ & $36 \pm 0 \cdot 7$ \\
mating & 180 & $7873 \pm 3004$ & $3222 \pm 1566$ & $40 \pm 3 \cdot 9$ \\
6h h after & 30 & $15012 \pm 3916$ & $4910 \pm 2783$ & $32 \pm 11 \cdot 4$ \\
mating & & & & \\
\hline
\end{tabular}

did not attach to the mucosa when they encountered the wall of the oviduct, while uncapacitated spermatozoa swam freely only until they encountered the mucosa and then became attached. However, occasionally we saw attached, uncapacitated spermatozoa detached from the mucosa and swim a short distance in the lumen before becoming attached again, indicating that at least some uncapacitated spermatozoa do not always attach firmly to the mucosa upon their first contact. When these spermatozoa were observed after flushing the oviduct with $50 \mu \mathrm{l}$ medium, all spermatozoa remaining in the oviduct were firmly attached to the mucosa and did not break free during the observation period.

Table 3. Mean number ( \pm s.d.) of spermatozoa attached to the hamster oviduct mucosa after flushing with uncapacitated and capacitated sperm suspensions $\left(1-2 \times 10^{6}\right.$ cells $\left./ \mathrm{ml}\right)(n=3)$

\begin{tabular}{lrr}
\hline \multirow{2}{*}{$\begin{array}{l}\text { Type of sperm } \\
\text { suspension }\end{array}$} & \multicolumn{2}{c}{ Segment of the oviduct } \\
\cline { 2 - 3 } & \multicolumn{1}{c}{ Isthmus } & Ampulla \\
\hline Uncapacitated & $105 \pm 67 \cdot 2$ & $148 \pm 90 \cdot 3$ \\
Capacitated & $4 \pm 2 \cdot 5$ & $2 \pm 2 \cdot 3$ \\
\hline
\end{tabular}

\section{Discussion}

Sperm storage in the oviducal isthmus is not unique to the hamster and several storage mechanisms have been suggested. However, most of these proposed mechanisms do not seem to be operating in the hamster. For example, in the mouse localized constriction of the isthmus was observed (Nilsson \& Reinius, 1969) and this was considered as a possible mechanism for immobilizing the spermatozoa in the isthmus (Suarez, 1987). Although localized constrictions do occur in the hamster isthmus during the preovulatory period (Battalia \& Yanagimachi, 1979), they are transient in nature and appear to be responsible for mixing the luminal contents rather than immobilizing spermatozoa.

Jansen (1978) suggested that a viscous mucus present in the isthmus of oestrous rabbits inhibits sperm passage through the isthmus. The oviduct of the oestrous hamster does not contain any distinct mucus (T. T. Smith \& R. Yanagimachi, unpublished observations), but it does contain cell debris similar to that observed in the mouse oviduct (Suarez, 1987), presumably derived from apocrine secretion of the mucosa. The role of this luminal debris in sperm transport is not clear, but it may act as a 'plug' to inhibit sperm ascent (Smith \& Yanagimachi, 1990). However, this debris is 
still present in the lumen near the time of ovulation when spermatozoa begin to ascend to the ampulla (T. T. Smith \& R. Yanagimachi, unpublished observations), so it does not act as an absolute barrier to sperm transport.

In the rabbit, the motility of spermatozoa recovered from the isthmus is depressed (Overstreet $\&$ Cooper, 1975) and this has been suggested as the major cause of limited sperm ascent in this species (Cooper et al., 1979). When we examined hamster spermatozoa through wall of the oviduct following natural mating, we also observed many immotile (dead) spermatozoa in the isthmic lumen (Smith \& Yanagimachi, 1990). At the same time, we observed many motile spermatozoa attached to the isthmic mucosa. In the hamster, this mucosal attachment appears to be the major factor responsible for the temporal storage of fertilizing spermatozoa in the isthmus.

In a previous study (Smith \& Yanagimachi, 1989), we collected fertile spermatozoa from the isthmus of mated hamsters, but were not certain whether these spermatozoa had been bound to the mucosa. Presumably some of them may have been recovered from the lumen and others from the mucosa. In the present study (Table 1), we clearly demonstrated that the spermatozoa which were firmly attached to the isthmic mucosa (those resistant to flushing) were capable of detaching, ascending to the ampulla and participating in fertilization. We cannot exclude the possibility that under normal in-vivo conditions spermatozoa that never attach to the isthmic mucosa can become capacitated and fertilize the eggs. However, the fact that the majority of viable spermatozoa were attached to the oviducal mucosa (Smith \& Yanagimachi, 1990) and the results of the present study, suggest that the majority of eggs are probably fertilized by spermatozoa that temporarily attach to the isthmic mucosa during storage.

Contact between spermatozoa and the mucosa is known to be beneficial for sperm survival both in vitro (Pollard et al., 1990) and in vivo (Smith \& Yanagimachi, 1990) and may be necessary for capacitation. Sperm attachment to the mucosa is not permanent. Otherwise, the spermatozoa that resisted flushing by remaining attached to the mucosa would not have been able to fertilize the eggs later. Since the number of spermatozoa that reach the ampulla is very low, even after all the eggs are fertilized (Cummins \& Yanagimachi, 1982; Smith et al., 1987), only a very small fraction of the thousands of spermatozoa stored in the isthmus must be released from the mucosa before and during fertilization. One of the experiments of the current study demonstrated that the spermholding capacity of the isthmic mucosa remained virtually unchanged before and during ovulation (Table 2). Therefore, it must be a change in sperm characteristics that is responsible for sperm release from the isthmic mucosa. Sperm capacitation appears to be involved in this change, as capacitated spermatozoa lose their affinity for the oviducal mucosa (Table 3). It was interesting that uncapacitated spermatozoa were capable of firmly attaching to both the isthmic and ampullary mucosa, suggesting that there is no major difference in the mucosal surfaces of these regions with respect to sperm attachment. Why then, do we not see spermatozoa attached to the mucosa of the ampulla shortly after mating? Perhaps all the live spermatozoa are confined to the isthmus and there is no mechanism to transport spermatozoa from the isthmus to the ampulla until about the time of ovulation.

In summary, it seems likely that spermatozoa remain attached to the isthmic mucosa until they become capacitated. It is only then that they are able to leave the isthmus and ascend to the ampulla. Capacitated, hyperactivated spermatozoa do not attach to the ampulla. Indeed, there would be no advantage for capacitated spermatozoa to have a high affinity for the ampullary mucosa when unfertilized eggs are present nearby. The fact that a very small fraction of the isthmic spermatozoa ever leave the isthmus suggests that only a very small number of spermatozoa complete capacitation in the isthmus.

This study was supported by the National Institutes of Health (HD-03402), BioScience Research Laboratory, Yamagata, Japan, and The University of Hawaii Research Council. We thank Mr K. Chiba for technical assistance and Dr E. Crichton for assistance with the manuscript. 


\section{References}

Battalia, D.E. \& Yanagimachi, R. (1979) Enhanced and co-ordinated movement of the hamster oviduct during the peri-ovulatory period. J. Reprod. Fert. 56, 515-520.

Cooper, G.W., Overstreet, J.W. \& Katz, D.F. (1979) The motility of rabbit spermatozoa recovered from the female reproductive tract. Gamete Res. 2, 35-42.

Cummins, J.M. \& Yanagimachi, R. (1982) Sperm-egg ratios and the site of the acrosome reaction during in vivo fertilization in the hamster. Gamete Res. 5, 239-256.

Flechon, J.E. \& Hunter, R.H.F. (1981) Distribution of spermatozoa in the utero-tubal junction and the isthmus of pigs, and their relationship with the lumenal epithelium after mating: a scanning electron microscope study. Tissue Cell 13, 127-139.

Hunter, R.H.F. (1984) Pre-ovulatory arrest and periovulatory redistribution of competent spermatozoa in the isthmus of the pig oviduct. J. Reprod. Fert. 72, 203-211.

Hunter, R.H.F. \& Wilmut, I. (1984) Sperm transport in the cow: peri-ovulatory redistribution of viable cells within the oviduct. Reprod. Nutr. Develop. 24, 597-608.

Hunter, R.H.F., Barwise, L. \& King, R. (1982) Sperm transport, storage, and release in the sheep oviduct in relation to the time of ovulation. Br. vet. J. 138, 225-232.

Jansen, R.P.S. (1978) Fallopian tube isthmic mucus and ovum transport. Science, NY 201, 349-351.

Nilsson, O. \& Reinius, S. (1969) Light and electron microscopic structure of the oviduct. In The Mammalian Oviduct, pp. 57-84. Eds E. S. E. Hafez \& R. J. Blandau. The University of Chicago Press, Chicago.

Orsini, M.W. (1961) The external vaginal phenomena characterizing the stage of the estrous cycle, pregnancy, pseudopregnancy, lactation, and the anestrous hamster, Mesocricetus auratus Waterhouse. Proc. Anim. Care Panel 11, 193-206.

Orsini, M.W. (1962) Technique of preparation, study and photography of benzyl-benzoate cleared material for embryological studies. J. Reprod. Fert. 3, 283-287.
Overstreet, J.W. \& Cooper, G.W. (1975) Reduced sperm motility in the isthmus of the rabbit oviduct. Nature, Lond. 258, 718-719.

Overstreet, J.W. \& Cooper, G.W. (1978) Sperm transport in the reproductive tract of the rabbit: II. The sustained phase of transport. Biol. Reprod. 19, 115-132.

Pollard, J.W., Plante, C., King, W.A., Hansen, P.J., Suarez, S.S. \& Betteridge, K.J. (1990) Sperm fertilizing capacity is maintained by binding to oviductal epithelial cells. In Fertilization in Mammals. Eds B. Bavister, J. Cummins \& E. R. S. Roldan. Serono Symposia, Norwell, MA, USA.

Smith, T.T. \& Yanagimachi, R. (1989) Capacitation status of hamster spermatozoa in the oviduct at various times after mating. J. Reprod. Fert. 86, 255-261.

Smith, T.T. \& Yanagimachi, R. (1990) The viability of hamster spermatozoa stored in the isthmus of the oviduct: the importance of sperm-epithelium contact for survival. Biol. Reprod. 42, 450-457.

Smith, T.T., Koyanagi, F. \& Yanagimachi, R. (1987) Distribution and number of spermatozoa in the oviduct of the golden hamster after natural mating and artificial insemination. Biol. Reprod. 37, 225234.

Suarez, S. (1987) Sperm transport and motility in the mouse oviduct: Observations in situ. Biol. Reprod. 36, 203-210.

Uto, N., Yoshimatsu, N., Lopata, A. \& Yanagimachi, R. (1988) Zona-induced acrosome reaction of hamster spermatozoa. J. exp. Zool. 248, 113-120.

Yanagimachi, R. (1982) In vitro sperm capacitation and fertilization of golden-hamster eggs in a chemically defined medium. In In Vitro Fertilization and Embryo Transfer, pp. 65-76. Eds E. S. E. Hafez \& K. Semm. MTP Press Ltd, Lancaster.

Yanagimachi, R. \& Chang, M.C. (1963) Sperm ascent through the oviduct of the hamster and rabbit in relation to the time of ovulation. J. Reprod. Fert. 6, 413-420.

Yanagimachi, R. \& Mahi, C.A. (1976) The sperm acrosome reaction and fertilization in the guinea-pig: a study in vivo. J. Reprod. Fert. 46, 49-54.

Received 18 June 1990 